\title{
Challenges in Thermal Welding of Aluminium Alloys
}

\section{Emil Schubert}

ABICOR Binzel, Giessen, Germany

Email: schubert@binzel-abicor.com

How to cite this paper: Schubert, E. (2018) Challenges in Thermal Welding of Aluminium Alloys. World Journal of Engineering and Technology, 6, 296-303.

https://doi.org/10.4236/wjet.2018.62018

Received: October 23, 2017

Accepted: May 8, 2018

Published: May 11, 2018

Copyright (C) 2018 by author and Scientific Research Publishing Inc. This work is licensed under the Creative Commons Attribution International License (CC BY 4.0).

http://creativecommons.org/licenses/by/4.0/

\begin{abstract}
Modern transport systems have the challenge to integrate more and more functions. This increases the weight of the structures. On the other hand demands and the legal regulations for emissions can only be fulfilled if the weight is reduced. This results in an ongoing increase of the usage of lightweight materials. Due to its low density and high strength Aluminium Alloys are the most used lightweight metals. However, some other physical properties hamper the processing of these alloys. The publication shows ways to overcome these challenges applying appropriate material preparation and handling in combination with specialized welding equipment for Aluminium welding. Application examples demonstrate the state of the art in Aluminium welding.
\end{abstract}

\section{Keywords}

Aluminium Alloys, Thermal Welding

\section{Potentials and Problems in Aluminium Welding}

Table 1 compares typical properties of Aluminium and Iron. These two metals characterize Aluminium alloys on the one side and steels on the other side.

The low density and the high specific strength of Aluminium alloys are the main reasons for the increased usage. Figure 1 shows the Aluminium usage [1].

The graph clearly shows that Aluminium use in cars will continuously increase over the next years. Other sources also show the material distribution for different materials in automotive industry since 1975. The usage of Aluminium was rising from $3 \%$ to $13 \%$ in the last 40 years.

The challenges to apply Aluminium are created by the high thermal conductivity, the melting points of the oxydes and the solubility for Hydrogen. In alloys additionally so-called hot cracking occurs due to the solidification kinetics. 
Table 1. Properties of aluminium compared to Iron.

\begin{tabular}{ccc}
\hline & $\mathrm{Al}$ & $\mathrm{Fe}$ \\
\hline Density $\rho\left[\mathrm{kg} / \mathrm{dm}^{3}\right]$ & 2.7 & 7.87 \\
Cristal lattice & cfo & cro \\
Young's modulus $\left[\mathrm{N} / \mathrm{mm}^{2}\right]$ & $\approx 71^{\star} 10^{3}$ & $\approx 210^{\star} 10^{3}$ \\
Tensile strength $\mathrm{R}_{\mathrm{m}}\left[\mathrm{N} / \mathrm{mm}^{2}\right]$ & $\approx 50$ & $\approx 200$ \\
Melting point $\left[{ }^{\circ} \mathrm{C}\right]$ & 660 & 1539 \\
Specific heat $\left[\mathrm{J} / \mathrm{kg}^{\circ} \mathrm{C}\right]$ & $\approx 896$ & $\approx 460$ \\
Electrical conductivity $\lambda_{\text {th }}\left[\mathrm{m} / \Omega^{\mathrm{mm}}{ }^{2}\right]$ & 36 & 8.3 \\
Thermal expansion coefficient $\left[1{ }^{\circ} \mathrm{C}\right]$ & $24^{\star} 10^{-6}$ & $12^{\star} 10^{-6}$ \\
Oxides & $\mathrm{Al}_{2} \mathrm{O}_{3}$ & $\mathrm{FeO}_{2}$ \\
& & $\mathrm{Fe}_{2} \mathrm{O}_{3}$ \\
& & $\mathrm{Fe}_{3} \mathrm{O}_{4}$ \\
Melting point of the oxides $\left[{ }^{\circ} \mathrm{C}\right]$ & $\approx 2050$ & $\approx 1400$ \\
Thermal conductivity $[\mathrm{W} / \mathrm{mK}]$ & & $\approx 1455$ \\
\end{tabular}

\section{Aluminium's march through the car continues; next stop Body-In-White}

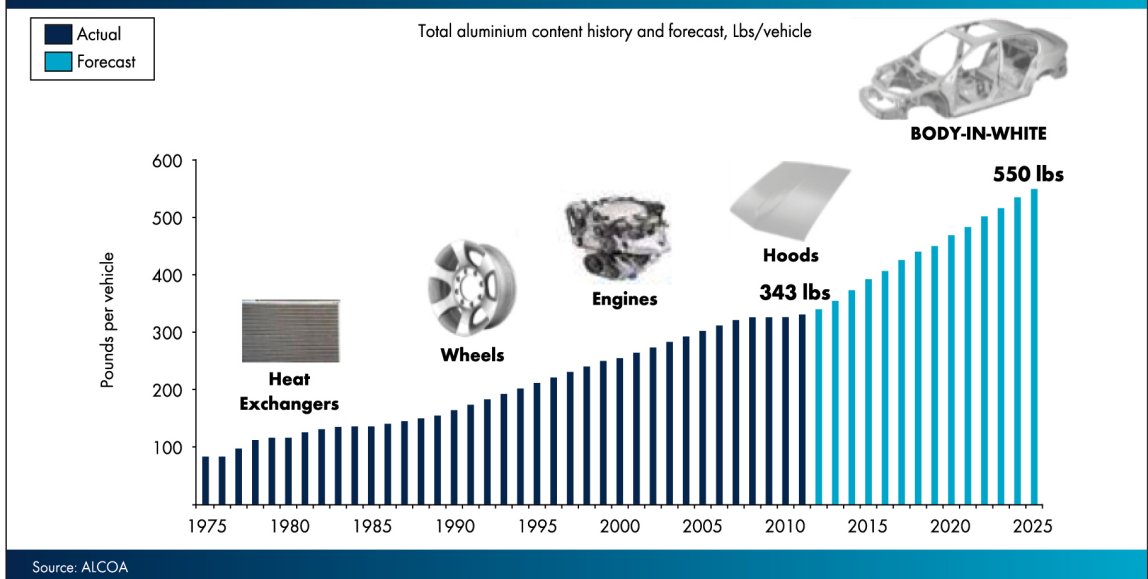

Figure 1. Aluminium usage in cars since 1975.

The high thermal conductivity requires a high heat-input, which in turn requires high rating of the welding equipment used.

The high melting point of Aluminium Oxyde of $2050^{\circ} \mathrm{C}$ compared to that of Aluminium of $660^{\circ} \mathrm{C}$ results in problems with energy coupling and instable welding processes.

The high solubility of hydrogen in liquid and the low solubility in solid hydrogen results in pore formation and hot cracking.

These problems require special attention during weld preparation, the weld itself and the welding equipment used [2]. The following section will cover these topics. 


\section{Welding of Aluminium Alloys (Weld Preparation, Welding Processes and Welding Equipment)}

\subsection{Weld Preparation}

In order to achieve a proper preparation both the Aluminium components and the used filler materials (mainly wires) have to be dry and clean and should be stored only for a minimum time to prevent oxide growth.

In automotive applications aluminium sheets get special coatings to prevent the uncontrolled growth of oxydes. In aerospace environments Aluminium sheets are even acid washed before welding. Other industries just use mechanical cleaning by brushing.

To lower the oxygen contents larger wire diameters for the filler wires are recommended in order to minimize the surface.

\subsection{Welding Processes and Welding Equipment}

Using appropriate equipment all generally used thermal welding processes can also be used for Aluminium alloys e.g. MIG, TIG, Plasma, Laser and Laser-MIG hybride processes.

In the beginning mainly TIG processes were used for Aluminium welding. Applying AC welding the oxide layer could be removed with the positive wave and the penetration was achieved with the negative wave [3].

Figure 2 displays the process principle and an example for a robotic TIG torch with integrated wire feeding.

For higher sheet thickness also Plasma welding can be used. Here welding with both DC or AC current is possible. In plasma welding higher welding speeds and even better surface quality is possible compared to TIG welding [4]. The user has to decide whether this weighs out the higher equipment costs.

Figure 3 shows the schematics of the process and typical examples for plasma welding torches.

To increase the welding speed also MIG welding is possible, because the metal transfer rate of MIG is higher as compared to TIG welding [5]. However, if the

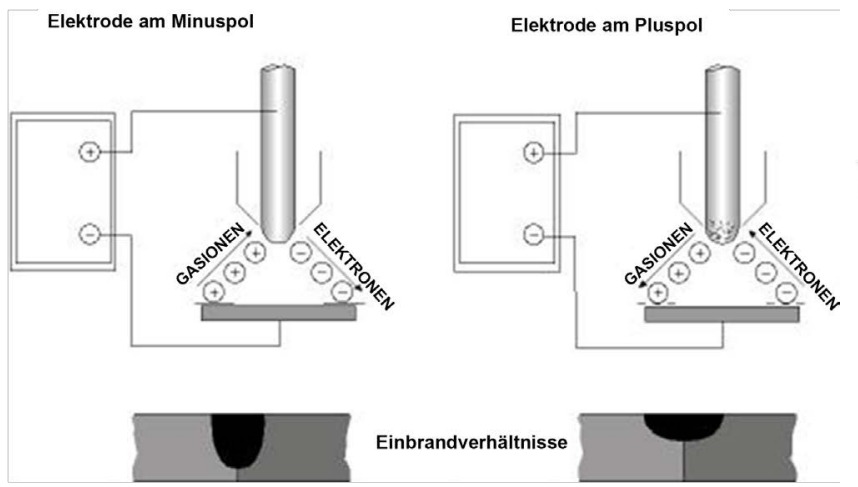

(a)

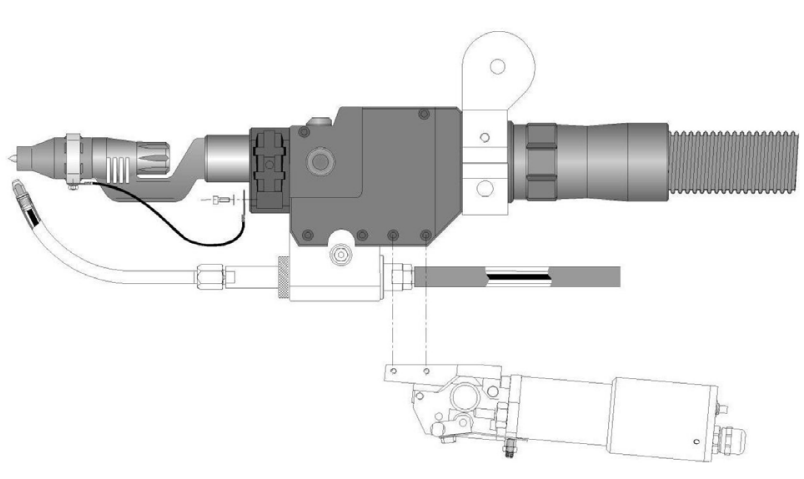

(b)

Figure 2. (a) Principles of AC TIG welding; (b) Robotic TIG welding torch (ABITIG WH) with integrated wire feeding, allowing automatic change of torch body for maintenance e.g. change of tungsten electrode. 


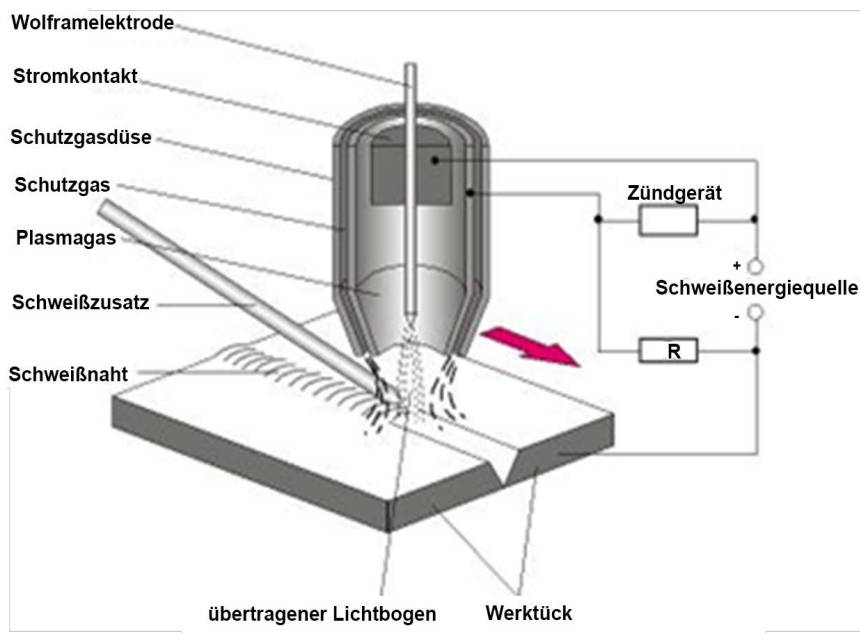

(a)

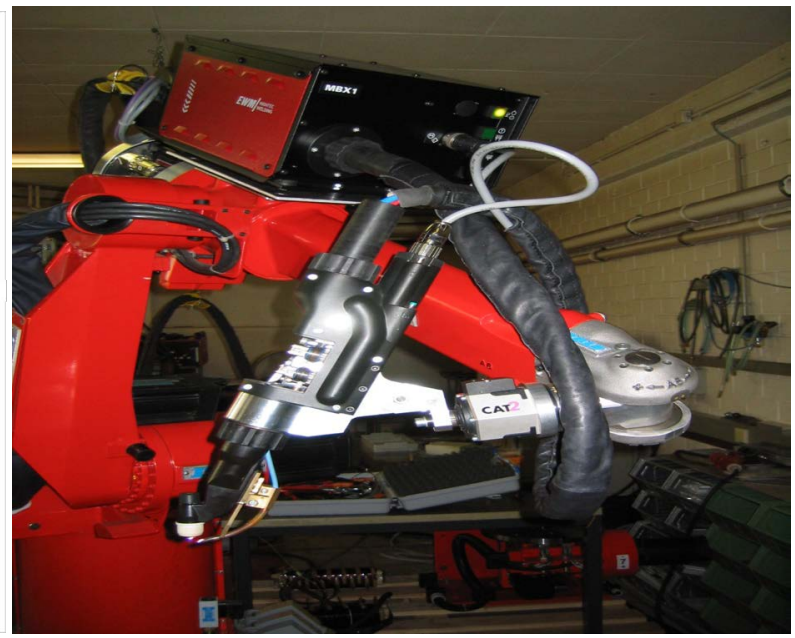

(b)

Figure 3. Principle of plasma welding and torch for automatized plasma welding (ABIPLAS WELD $100 \mathrm{~W}$ ).

speed is too high, hydrogen in the liquid metal may not be able to escape before solidification and then form pores. For thin sheet applications also pulsed welding, AC welding or modified short arc processes are used.

Figure 4 \& Figure 5 show the schematics of the MIG welding process and a typical MIG welding torch. Due to the high heat-input (also from reflections from the surface) torches with double cooling circuit are recommended.

In order to optimize wire feeding for Aluminium Welding ABICOR Binzel developed a special wire feeding concept called Master Feeder System (MFS).

Figure 6 \& Figure 7 shows the Modular Feeder concept. The core components are two exactly synchronized wire feeders that allow to use different wire packages and also different processes (MIG, TIG, Plasma, Laser, LASER-MIG).

\section{Examples for Applications}

Manual applications for Aluminium Welding are well-known.

Figure 8 illustrates TIG welding of Aluminium ladders and TIG welding of bicycle frames.

The TIG torch that is applied here, has a very high rating, combined with a small volume. The small volume allows welding also in very restricted areas. These ABITIG torches have only three spare parts, compared to the so-called Linde style TIG torches with 5 parts that have to be replaced regularly.

Figure 9 shows MIG welding of Aluminium components made of sheets and for profiles.

The first industrial robotic applications were developed in the 2000 nds. ABICOR Binzel introduced robotic welding of Aluminium in the first Audi A8 series. Several other models followed. Figure 10 shows an application at the Audi A2 model.

Today also the Audi A6 axles are welded using the ABICOR Binzel MFS system and ABIROB A torches. 


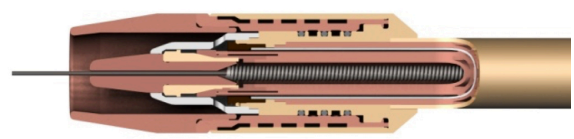

(a)

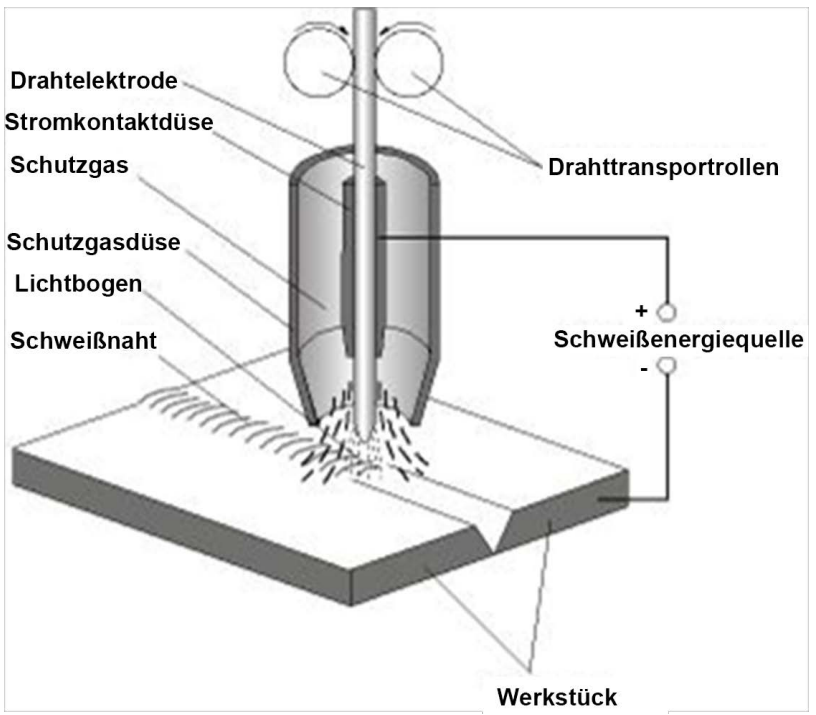

(b)

Figure 4. Principle of MIG welding and MIG torch (ABIMIG $535 \mathrm{~W}$ ) with double-cooling circuit.
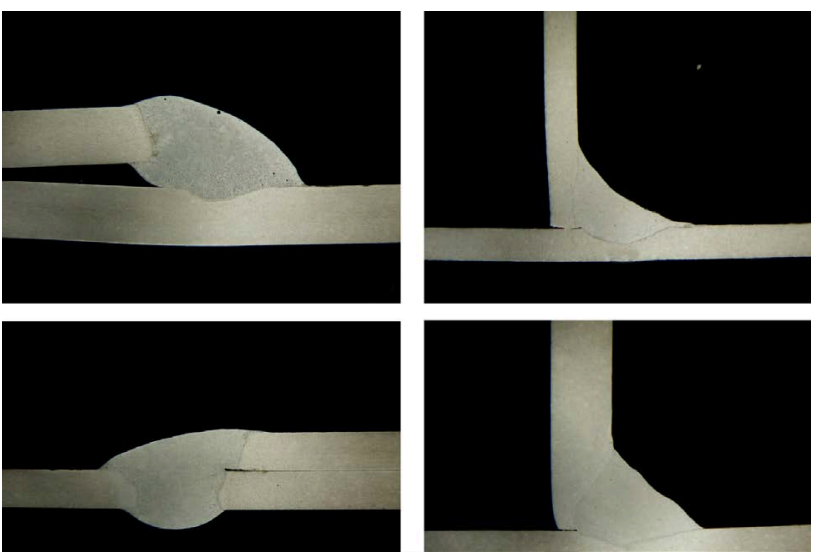

Figure 5. Examples for thin AC MIG welded AlMg thin sheet alloys are shown.

Figure 11 shows an application for truck trailers. Profiles made form AlMg 4.5 had to be welded with overlap and V-joints.

\section{Summary and Outlook}

The challenges that Aluminium alloys show for thermal joining processes can be overcome by process knowledge, correct weld preparation and by using appropriate equipment. This allows making use of the huge lightweight potential of Aluminium alloys especially in lightweight design. 


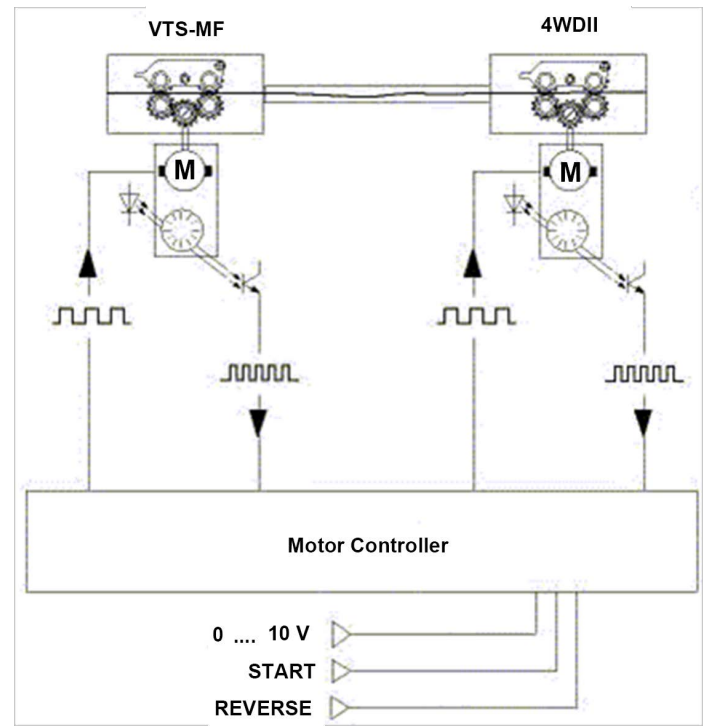

Figure 6. Modular wire feeder concept master feeder system (MFS).

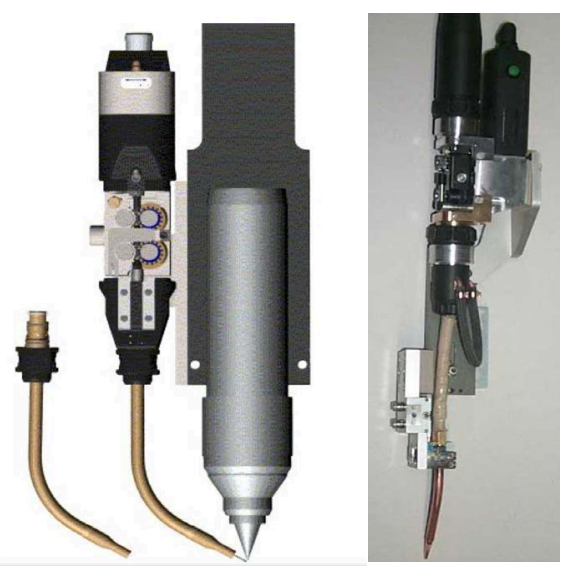

Figure 7. Front-end of master feeder system, designed for laser welding and brazing.

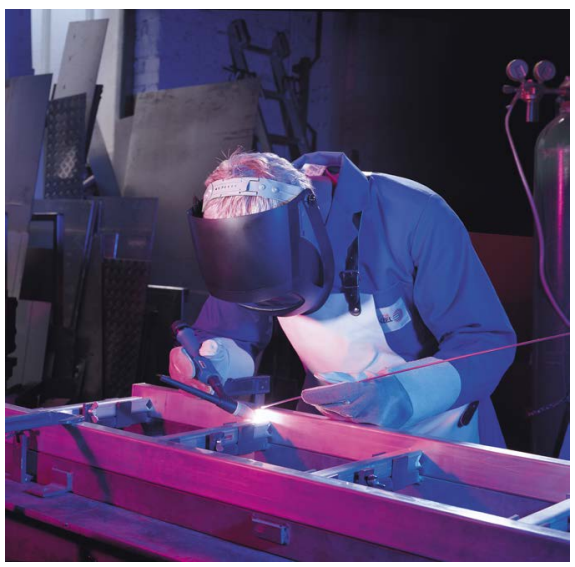

(a)

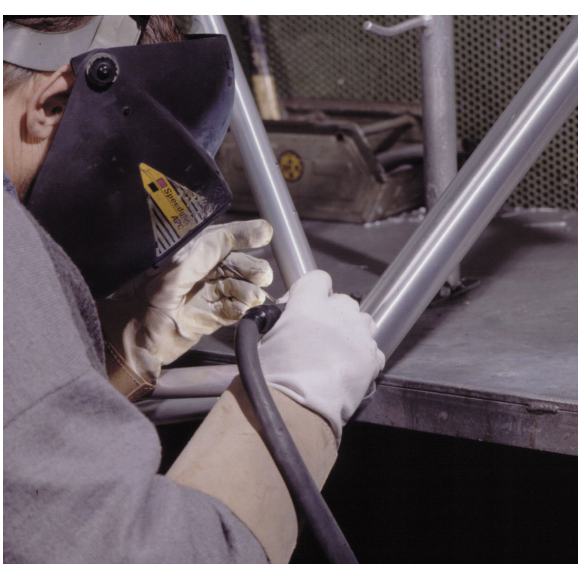

(b)

Figure 8. Manual TIG welding of aluminium ladders using ABITIG $450 \mathrm{~W}$ torch. 


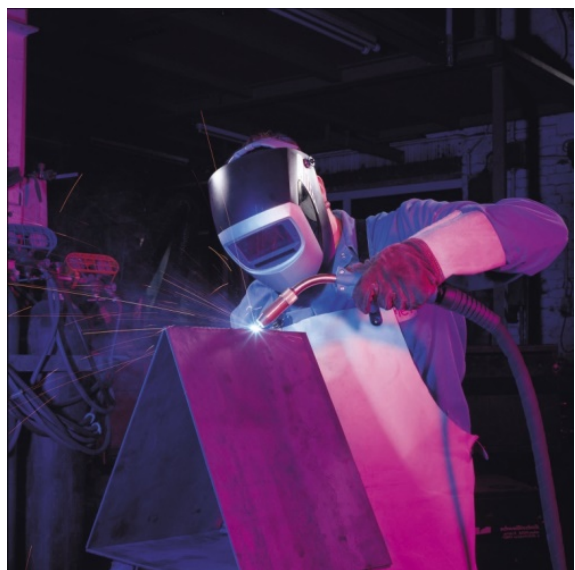

(a)

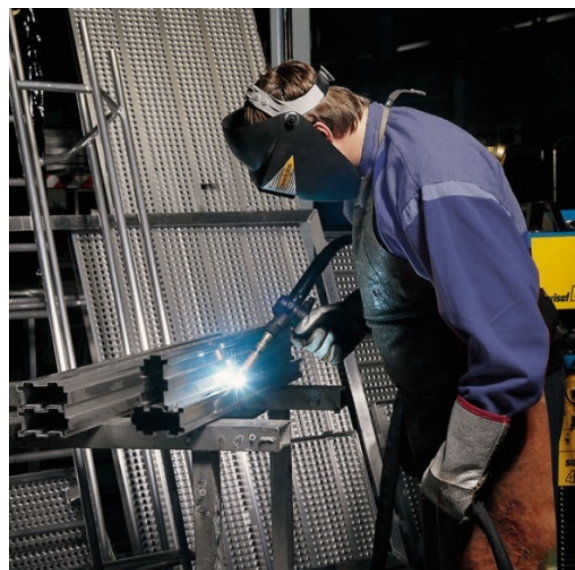

(b)

Figure 9. Manual MIG welding of (a) Aluminium edge seam and (b) MIG manual push-pull welding of Aluminium profiles.
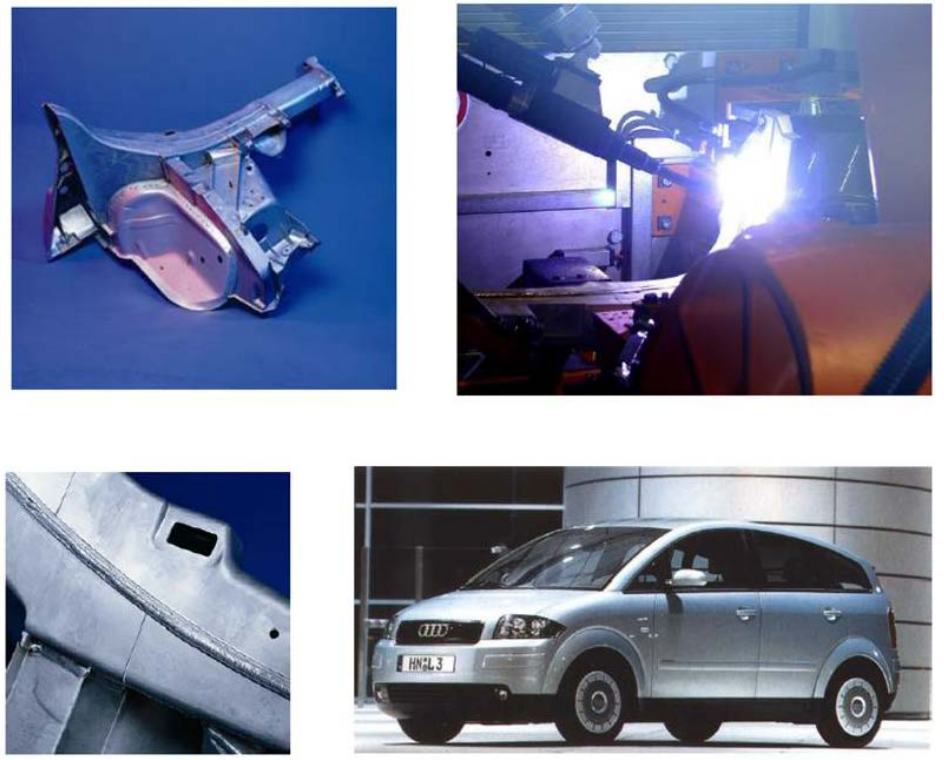

Figure 10. Aluminium welding at Audi A2.

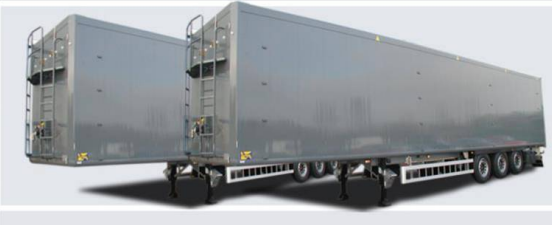

(a)

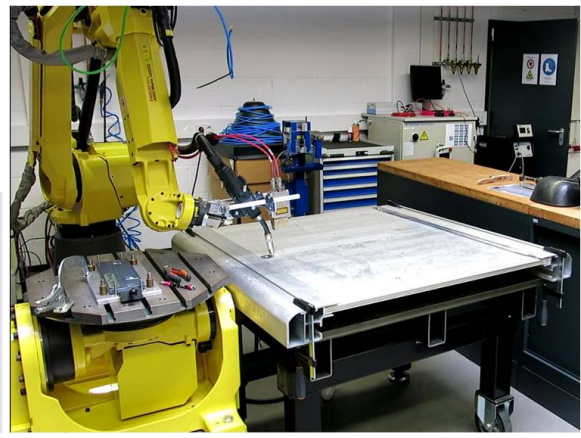

(b)

Figure 11. Aluminium truck trailers welded with BinzeliROB power source, ABIROB WH W 500 robotic torch and seam tracking sensor Th6D. (a) truck trailer (b) sample part for weld trials. (a) Truck trailer made from AlMg 4.5; (b) Sample part welding. 
The use of Aluminium applications is still increasing and thermal joining processes will have to be further elaborated to increase reliability and compatibility with surrounding components e.g. the different types of welding robots.

Also welding of material combinations e.g. Aluminium to steel or to Titanium has to be treated.

\section{References}

[1] Decker Worldwide Study: Aluminium Usage in Cars (2011).

[2] White, G. (2015) Best Practices for Welding Aluminum. https://www.thefabricator.com/article/aluminumwelding/best-practices-for-welding -aluminum

[3] (1995) Welding Handbook, Vol. 2. American Welding Society, Miami, 74-107.

[4] Lu, M.J. (1987) Power-Inputs in Gas Metal Arc Welding of Aluminium. Welding Journal, 68, 382-452.

[5] Klyselica, S. (1987) High-Frequency Reversing Arc Switch for Plasma Arc Welding of Aluminium. Welding Journal, 66, 31-35. 